\title{
Nuclear Magnetic Resonance Relaxometry and Thermoelectrodynamic Spectroscopy Study of Heat Accumulating/Emitting Salt $\mathrm{CaCl}_{2} \cdot \mathbf{6} \mathrm{H}_{2} \mathrm{O}$
}

\author{
Kashaev R.S.-H. \\ Kazan State Power Engineering University,420107, Kazan, Esperanto, 62-29 \\ *Corresponding Author: kashaev2007@yandex.ru
}

Copyright (C) 2014 Horizon Research Publishing All rights reserved.

\begin{abstract}
Using nuclear magnetic resonance relaxometry and thermoelectric dynamical methods studied phase transitions and electric power generation properties of hydrate salt $\mathrm{CaCl}_{2} \cdot 6 \mathrm{H}_{2} \mathrm{O}$. It can be used as a phase-changing materials (PCM) for heat accumulating/emitting thermal electric energy storage. For studies of phase transitions temperature and time dependences on protons was used Portable Relaxometer NMR NP-2 on resonance frequency $v_{\mathrm{o}}$ $=14,5 \mathrm{M} Ц$. Was received data on structure-dynamical NMR-parameters, determining phase transition properties of salt.
\end{abstract}

Keywords Nuclear Magnetic Resonance Relaxometry, Thermoelectrodynamic spectroscopy, Phase Transitions

\section{Introduction}

Direct electric energy production using thermoelectric Seebeck effect in new renewal electric energy sources is of great technology relevance. Use of phase transitions(PT) in phase-changing materials has high perspectives. But the discovery of PT mechanism is one of the great physic problems [1]. Solution of it gives an opportunity for use of ambient temperature changes during 24 hours, especially in deserts and regions with sharp continental climate. At present time such materials, named thermal energy storage systems, are widely used in air conditioning systems for their benefits on energy conservation [2].Phase transitions in hydrated salts and paraffins due to their low temperatures of PT [3] can also be used for power generation transformation of heat of fusion/crystallization in electric current power as a most convenient form of energy. For this purpose can be used the thermoelectric Seebek effect of electricity production using temperature overfall during the process of PT at heating and cooling.[4].But phase transitions are not studied completely and is a complicated phenomena and by Noble laureate V.L.Ginsburg are put on the seventh place among problems, needed to be solved [1].

\section{Samples, Apparatus and Methods}

For study were used hydrated salts: $\mathrm{CaCl}_{2} \cdot 6 \mathrm{H}_{2} \mathrm{O}$, $\mathrm{Na}_{2} \mathrm{SO}_{4} \cdot 10 \mathrm{H}_{2} \mathrm{O}, \quad \mathrm{Na}_{2} \mathrm{~S}_{2} \cdot 5 \mathrm{H}_{2} \mathrm{O}, \quad \mathrm{CH}_{3} \mathrm{COONa} \cdot 3 \mathrm{H}_{2} \mathrm{O}$. Their phys-chemical properties-temperatures of melting $T_{\text {melt }}{ }^{\circ} \mathrm{C}$, heat of melting, $Q_{\mathrm{m}}(\mathrm{kJ} / \mathrm{mol})$ and density $\rho\left(\mathrm{kg} / \mathrm{m}^{3}\right)$, taken from $[2,3]$, are presented in Table 1 .

As it is seen from the table, essential dispersion of the parameters obtained by different authors is observed. In our opinion the reason of such data dispersion is the complex form of PT in this TES. The aim of this work - is the study and attempt of understanding by two experimental methods (NMR and thermoelectric dynamical spectroscopy) the peculiarities of phase transitions in $\mathrm{CaCl}_{2} \cdot 6 \mathrm{H}_{2} \mathrm{O}$.

Table 1

\begin{tabular}{|c|c|c|c|}
\hline Salt & $T_{\text {melt }}\left({ }^{\circ} \mathrm{C}\right)$ & $Q_{\mathrm{m}}(\mathrm{kJ} / \mathrm{mol})$ & $\rho\left(\mathrm{kg} / \mathrm{m}^{3}\right)$ \\
\hline $\mathrm{CaCl}_{2} \cdot 6 \mathrm{H}_{2} \mathrm{OFSP} 42-0006-($ pharm$)$ & $29,7[3] ; 29,2 ; 29,7 ; 30[2]$ & $170[3] ; 190,8 ; 171 ; 174,4 ; 192[2]$ & $1562\left(38.77^{\circ} \mathrm{C}\right) ;$ \\
\hline $\mathrm{Na}_{2} \mathrm{~S}_{2} \cdot 5 \mathrm{H}_{2} \mathrm{O}$ & $48[3] ;$ & $1802(\mathrm{solid}) ; 1710(\mathrm{solid})[2]$ \\
\hline $\mathrm{GOST} 27068-86$ & $58 ; 48-49[2]$ & $210[3] ; 201 ; 209.3 ; 187[2]$ & $1600[3] ; 1600(\mathrm{solid}) ; 1666 ; 1662[2]$ \\
\hline $\mathrm{CH}_{3} \mathrm{COONa} \cdot 3 \mathrm{H}_{2} \mathrm{O}$ & $58,2[2]$ & $260[2]$ & $1450[2]$ \\
\hline $\mathrm{H}_{2} \mathrm{O}$, Distillate & $0[3]$ & $333[2]$ & $998\left(20^{\circ} \mathrm{C}\right) ; 917(\mathrm{ice})[2]$ \\
\hline
\end{tabular}




\section{NMR-Relaxation Parameters Measurements}

Measurements of NMR-relaxation structure-dynamical parameters (SDP): spin-lattice $T_{1 \mathrm{i}}$, spin-spin $T_{2 \mathrm{i}}$ relaxation times and corresponding to them proton phases populations $P_{1,2 \mathrm{i}}$ were realized on the Portable Relaxometer NMR NP-2 (designed and produced by CBRC, Kazan, Republic of Tatarstan, RF) and presented at fig.1 [5] at resonance frequency $v_{0}=14,5 \mathrm{MHz}$.

Magnetic field is formed by $\mathrm{NdFeB}$ permanent magnet with field inhomogeneity $\delta H<5 \cdot 10^{-4}$ equiped with adjustable NMR probe-head $\varnothing 30 \mathrm{~mm}$. Temperature of samples were changed and maintained with accuracy $\pm 0,2^{\circ}$ by thermo stabilization device, described in Patent of RF [6].

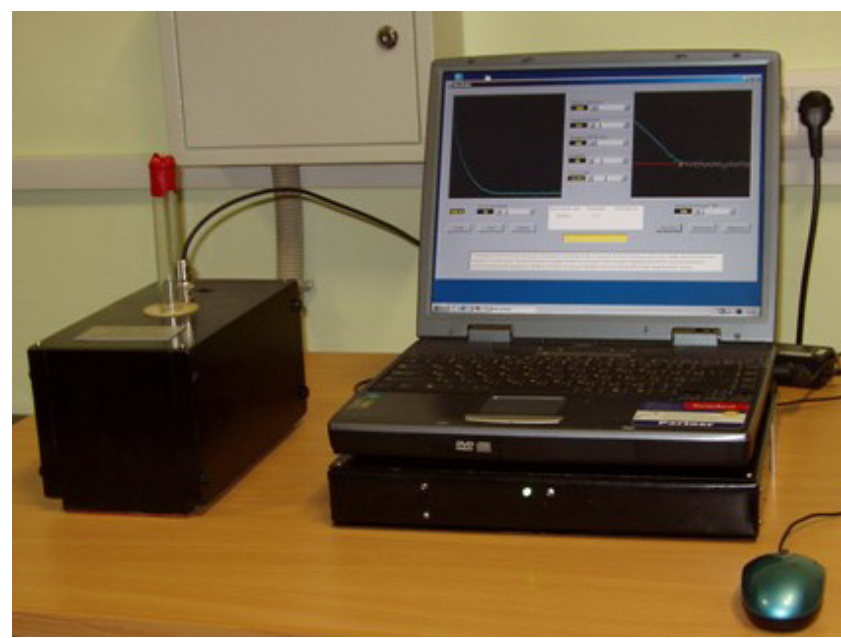

Figure 1. Portable Relaxometer NMR NP-2

Spin-lattice $T_{11}$ relaxation times were determined using spin-echo recovery sequence $90-\tau-90^{\circ}-\tau_{0}-180^{\circ}$ of Hahn [7]. Measurement parameters were: pulses repetition delay time $T=9 \mathrm{~s}$, number of pulses steps $N=100$ with a step $\tau=3 \mathrm{~ms}$, $\tau_{0^{-}} 200 \mu \mathrm{s}$, number of accumulations $n=3$.For spin-spin $T_{2 \mathrm{i}}$ relaxation times measurements $90^{\circ}-\tau-\quad\left(180^{\circ}-2 \tau-\right)_{\mathrm{N}}$ sequence of Carr-Purcell-Meiboom-Gill [8] was used, eliminating influence of self-diffusion and protons exchange. $T_{2 \mathrm{i}}$ were measured with delay time $T=9 \mathrm{~s}$, number of $180^{\circ}$ pulses $N=900$, interval $\tau$ between $180^{\circ}$ pulses $-200 \mu \mathrm{s}$, number of accumulations $n=10$.

Main instrumental error was: $\gamma_{0}= \pm 1,44 \%$.Experimental error of relaxation times measurements: for $\pm 3 \div 4 \%$ and $\pm 2 \%$ for NMR-signal amplitudes recurrence, depending from accumulations number $n$, so error could be reduced $(n)^{1 / 2}$ times using $n$ accumulations. Sample probe head has $\varnothing 30 \mathrm{~mm}$, so the sample volume $V$ for probe filling height $h=$ $35 \mathrm{~mm}$ was $V=25 \mathrm{~cm}^{3}$, large enough for sample representation. Coefficient of sensibility $K=v^{2} V\left[\mathrm{MHz}^{2} \mathrm{~cm}^{3}\right]$ in used NMR-relax meter is $K=4150 \mathrm{MHz}^{2} \mathrm{~cm}^{3}$, that is close to $K=1600-6400 \mathrm{MHz}^{2} \mathrm{~cm}^{3}$ of "Minispec pc120" (Bruker, Germany).

Spin-echo amplitudes $A_{\mathrm{e}}$ envelopes dependences in Hahn and CPMG-methods (presented as curves on computer monitor at fig.2 a,b) after amplitude detection had forms, which can be described by equations:

$$
\begin{gathered}
A_{e}=1-\sum_{i=A, B, C} A_{1 \mathrm{i}} \exp \left(-t / T_{1 \mathrm{i}}\right) \\
A_{\mathrm{e}}=\underset{\substack{i=A, B, C \\
i=A \mathrm{i}}}{A_{2 \mathrm{i}} \exp \left(-t / T_{2 \mathrm{i}}\right)}
\end{gathered}
$$

where $A_{1 \mathrm{i}}$ and $A_{2 \mathrm{i}}$ (in arbitrary units) correspond to initial amplitudes of proton and $B$ phases of different types of water protons motions which determine relaxation times $T_{1 \mathrm{i}}$ and $T_{2 \mathrm{i}}$. From measured spin-echo amplitudes data logarithms were taken, and the curves were decomposed on three linear components, corresponding to $T_{1,2 \mathrm{~A}}$ and $T_{1,2 \mathrm{~B}}$.

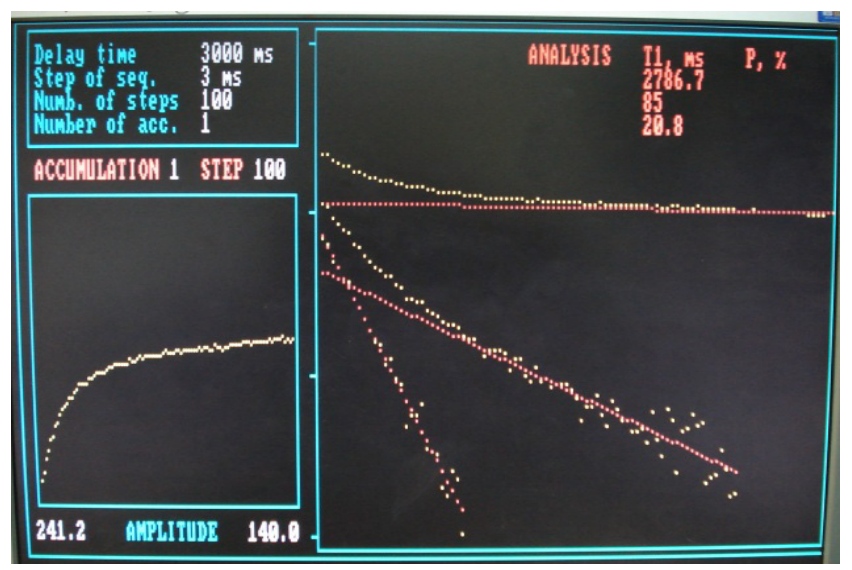

Figure 2. Decomposition of the polyexponential envelope of the spin-echo signals into three Lorenz exponentials with their $T_{1 \mathrm{i}}$ relaxation times and proton populations.

Term "proton phase" does not correspond to aggregate state, but to protons with relaxation, caused by dipole-dipole interactions in different states and environment.

For sufficient number of experimental points (more, than 100), reverse Laplace transformation $\left(L^{-1}\right)$ can be used and the time dependence of signal $\left(A_{\mathrm{e}}=\sum A_{2 \mathrm{i}} \exp \left(-t / T_{2 \mathrm{i}}\right)\right)$ can be transformed in delta-function $\delta\left(t-T_{2 \mathrm{i}}\right)$ i.e. function of $T_{2 \mathrm{i}}$ appearence probability [9] using CONTIN, DASHA, UPEN programs. So the relaxation times distribution can be determined. However, the demand of noise low level $S / N<$ 100 to avoid displacements of $T_{1,2 \mathrm{i}}$ values and distortions of weight coefficients is difficult to fulfill. Such level of $S / N$ is a usual case in experiment. At $S / N=10$ use $L^{-1}$ transformation will give error in $20 \%$ [10]. At the same time relaxation function can be approximated by the sum of exponents if $T_{1,2 \mathrm{i}}$ difference is large enough [11]. It is really so in our case, and for relaxation times determination we used graph-analytical method of spin-echo envelopes dependences decomposition, described earlier in [12].

Molecular motion activation energies $E_{A}$ of the linear parts of $T_{1}$ and $T_{2}$ were determined from reverse temperatures $\left(10^{3} / T\right)$ dependences using Advanced Grafer program. At high temperature approximation $2 \pi v_{0} \tau_{c}<<1$ correlation times $\tau_{\mathrm{c}}($ time of living of protons in definite position) can be described by Arrenius equation $\tau_{\mathrm{c}}=\tau_{\mathrm{o}} \exp \left(E_{\mathrm{A}} / R T\right)$, where $\tau_{\mathrm{o}^{-}}$ period of atom oscillation, $R=8,314 \mathrm{~J} / \mathrm{mol}$ - universal gas 
constant. In such conditions, the relaxation times are equal $T_{1}$ $=T_{2}$, and for intramolecular contribution in relaxation the activation energy $E_{\mathrm{A}}$ can be determined using values of relaxation times $T_{1,2}{ }^{(2)}$ and $T_{1,2}{ }^{(1)}$, measured at temperatures $T^{(1)}$ and $T^{(2)}$ [13] using equation:

$$
E_{\mathrm{A}}\left(\mathrm{J} / \text { mole }=19,13 \lg \left(T_{1,2}{ }^{(2)} / T_{1,2}{ }^{(1)}\right)\left[T^{(1)} T^{(2)} /\left(T^{(2)}-T^{(1)}\right)\right],\right.
$$

Error of $E_{\mathrm{A}}$ determination is the sum of instrumental, relaxation times and temperature measurements errors:

$$
\Delta E_{\mathrm{A}} / E_{\mathrm{A}}=\Delta \lg T_{1,2} / \lg T_{1,2}+\Delta T^{(1)} / T^{(1)},
$$

and equal to $\gamma_{\mathrm{E}}= \pm(1,4+3,5+0,4) \approx \pm 5 \%$.

\section{Thermoelectrodynamic Measurements}

Techniques used to study phase transitions are usually conventional calorimetric, differential scanning calorimetric (DSC) and differential thermal analysis (DTA). As it is mentioned by Gibbs [ref.71 in 2], there is considerable uncertainty about the property values provided by manufacturers. Yinping [ref.72 in 2] reviewed conventional calorimetric methods and pointed out their limitations such as: a) too small quantities of sample can be analyzed (1-10 $\mathrm{mg}$ ), but some properties depend on sampler volume; b) phase changes cannot be visually observed. According to [14] error of DTA reach $\pm 3 \%$ at measurement range ends. Taking it in consideration we elaborated device, structure scheme of which is presented at fig.3. It is the combination of the common and differential calorimetry additionally determining Seebeck thermoelectric tension $U$ and current $I$ of endo/exothermic effects in great volumes from temperature and time. It may be called thermoelectrodynamical spectroscopy (TEDS) method, because using it we can reveal the fine structure of phase transitions.

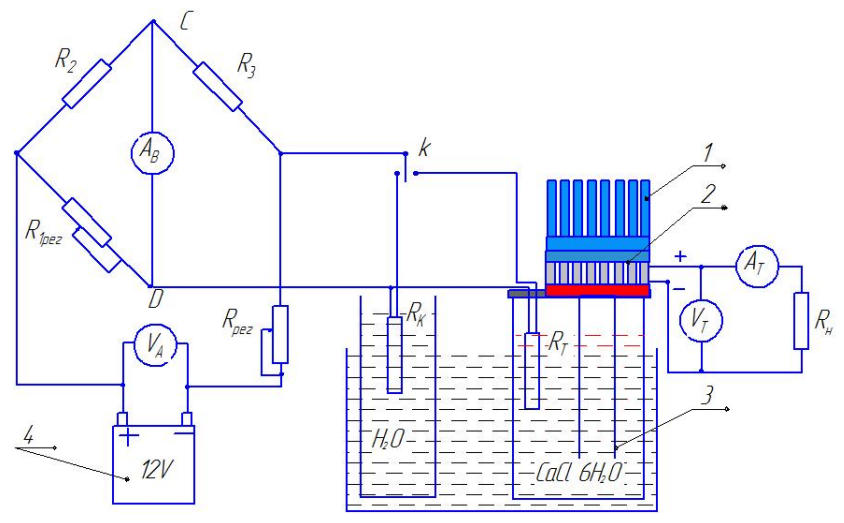

Figure 3. Device for receiving the dependences of the thermo electric tension (TET) and current from temperature and time using. Here 1- radiator; 2 -thermoelectric element (TE)TEMO-7; 3 - thermostate; 4 - accumulator $12 \mathrm{~V}$ controlled by voltmeter $V_{A} ; R_{2}$ and $R_{3}$ - resistors in Winston bridge shoulders; $R_{\text {reg }}$ - potentiometer for initial currents balancing; $R_{\text {reg }}-$ potentiometer for accumulator tension regulation; $R_{1}-$ load resistor; $R_{\mathrm{T}}$ and $R_{\mathrm{K}}-$ thermo resistors for salt and water temperatures measurements; $A_{B}$ current balance meter; $A_{T}$ and $V_{T}$-current and tension meters on TE.

Small thermoelectric element TEMO-7 (40x60 mm) was used. One solder of it is connected with heat conducting plate, immersed in salt. Another solder is connected with radiator, freezed by cooler or ice. Point of melting usually is determined during 15 minutes. But we cooling process controlled during 100-180 minutes in the sample of volume $V \approx 100 \mathrm{ml}$. Temperatures in sample and water were measured by precision $R=50 \mathrm{Ohm}$ thermoresistors of the II class $\left(\Delta t= \pm\left(0,30+3,5 \cdot 10^{-3} t\right)\right.$ in the temperature range $50^{\circ} \mathrm{C} \leq T \leq+180^{\circ} \mathrm{C}$, maintained with Winston bridge. Resistivity is determined from equation $R_{\mathrm{t}}=R_{\mathrm{o}}(1+\alpha T)$, where $\alpha=4,26 \cdot 10^{-3} \mathrm{~K}^{-1}$. Measurement error was $\pm 0.2 \%$.

\section{Experimental Results}

Results of calorimetric measurements are presented at fig.4-5. At fig.4 is differential calorimetric curve of $\mathrm{CaCl}_{2} \cdot 6 \mathrm{H}_{2} \mathrm{O}$, on fig. 5 - time dependences of temperature, thermoelectricity tension $\mathrm{U}(\mathrm{t})$ of $\mathrm{CaCl}_{2} \cdot 6 \mathrm{H}_{2} \mathrm{O}$ and water.

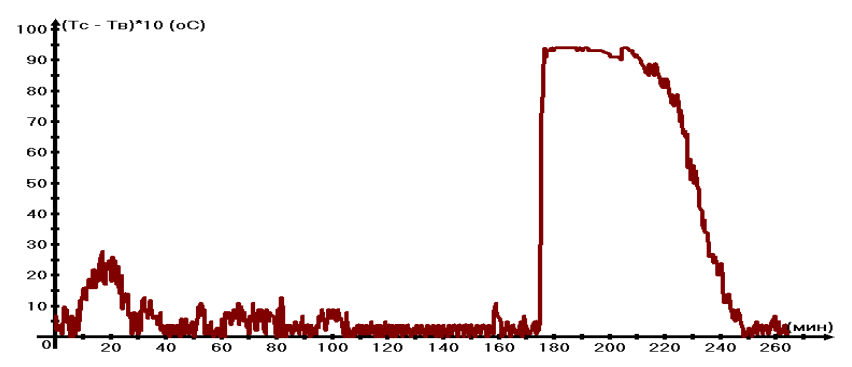

Figure 4. Time dependence of differential calorimetric curve of $\mathrm{CaCl}_{2} \cdot 6 \mathrm{H}_{2} \mathrm{O}$ at natural cooling from $70^{\circ} \mathrm{C}$ till $20^{\circ} \mathrm{C}$

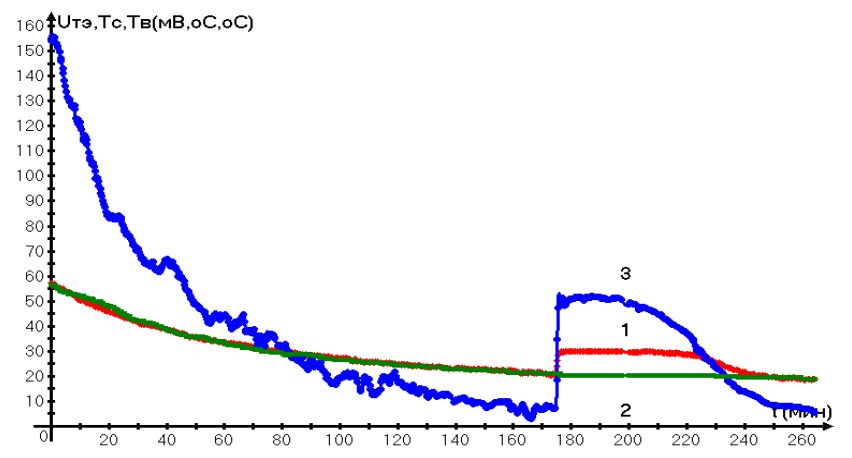

Figure 5. Time dependences of temperature (curve 1), thermoelectricity electric tension (curve 2) and current (curve 3) of $\mathrm{CaCl}_{2} \cdot 6 \mathrm{H}_{2} \mathrm{O}$ and water at cooling process from $67^{\circ} \mathrm{C}$ to $20^{\circ} \mathrm{C}$

As it is seen from fig. 4 thermogramm curve has a complex form and first temperature increment $\Delta T_{\mathrm{e}}(T)=$ $2.5^{\circ} \mathrm{C}$ is observed at $t=10 \mathrm{~min}$, but the main exothermic effect increment appears at $t=180 \mathrm{~min}$. At fig. 5 in the melted salt during cooling process main exothermic temperature $T_{\mathrm{e}}$ peaks (temperature increment $\Delta T_{\mathrm{e}}$, followed by the plato - curve 1) appear at 180-th minute. The peak coincides with thermoelectric tension curve $3 U(t)$. Heat exothermic emission lastы 70 minutes on thermoelement TEMO-7 and 6 hours on TEC-127-06C. In water such exothermic effects are not observed (curve 2). 
Compare $\mathrm{CaCl}_{2} \cdot 6 \mathrm{H}_{2} \mathrm{O}$ exothermic temperature increment with such in $\mathrm{Na}_{2} \mathrm{~S}_{2} \cdot 5 \mathrm{H}_{2} \mathrm{O}$ and $\mathrm{CH}_{3} \mathrm{COONa} \cdot 3 \mathrm{H}_{2} \mathrm{O}$ (see Table 2) it can be seen, that $\Delta T_{\mathrm{e}}(T)$ increases with number of hydrated water molecules sited in tetrahedral voids of crystal giving maximal thermoelectric tension $\Delta U=45 \mathrm{mV}$ with heat emission duration $\Delta T_{\mathrm{e}}=55 \mathrm{~min}$ for $\mathrm{CaCl}_{2} \cdot 6 \mathrm{H}_{2} \mathrm{O}$ and $\Delta U=$ $750 \mathrm{mV}$ on TEC-127-06C made from modern material and several times greater solders surface square.

Table 2

\begin{tabular}{|c|c|c|c|}
\hline Salt & $\Delta U(\mathrm{mV})$ & $T_{\mathrm{e}}\left({ }^{\circ} \mathrm{C}\right)$ & $\Delta t_{\mathrm{e}}(\mathrm{min})$ \\
\hline $\mathrm{CaCl}_{2} \cdot 6 \mathrm{H}_{2} \mathrm{O}$ & 45 & $29.2-30[2,3]$ & 55 \\
\hline $\mathrm{Na}_{2} \mathrm{~S}_{2} \cdot 5 \mathrm{H}_{2} \mathrm{O}$ & 15 & 43 & 22 \\
\hline $\mathrm{CH}_{3} \mathrm{COONa} \cdot 3 \mathrm{H}_{2} \mathrm{O}$ & 5 & 60 & $1-2$ \\
\hline
\end{tabular}

Before exothermic phase transition, the temperature curves of both water and salt coincide with each other (see curves 1 and 3 at fig.5) and with correlation coefficient $R^{2}=0,873$ are described by equation:

$$
T_{B}=T_{C}=43,48 \exp (-0,00375 t),
$$

So, from the position of most effective phase changing salt is $\mathrm{CaCl}_{2} \cdot 6 \mathrm{H}_{2} \mathrm{O}$ and it can be used for design as thermoelectric generator.

To reveal the reason of it we studied the salt using nuclear magnetic resonance relaxometry.

\subsection{Experimental Results of NMR-Relaxation Analysis and Discussion of Them}

Results of measurement of spin-lattice $T_{1 \mathrm{~A}}, T_{1 \mathrm{~B}}$ and spin-spin relaxation $T_{2 \mathrm{~A}}, T_{2 \mathrm{~B}}$ times from inverse temperature $10^{3} / \mathrm{T} \mathrm{K}$ in $\mathrm{CaCl}_{2} \cdot 6 \mathrm{H}_{2} \mathrm{O}$ are presented at fig.6, time dependences of relaxation in temperature interval of phase transition $18-26^{\circ} \mathrm{C}-$ on fig. 7 .

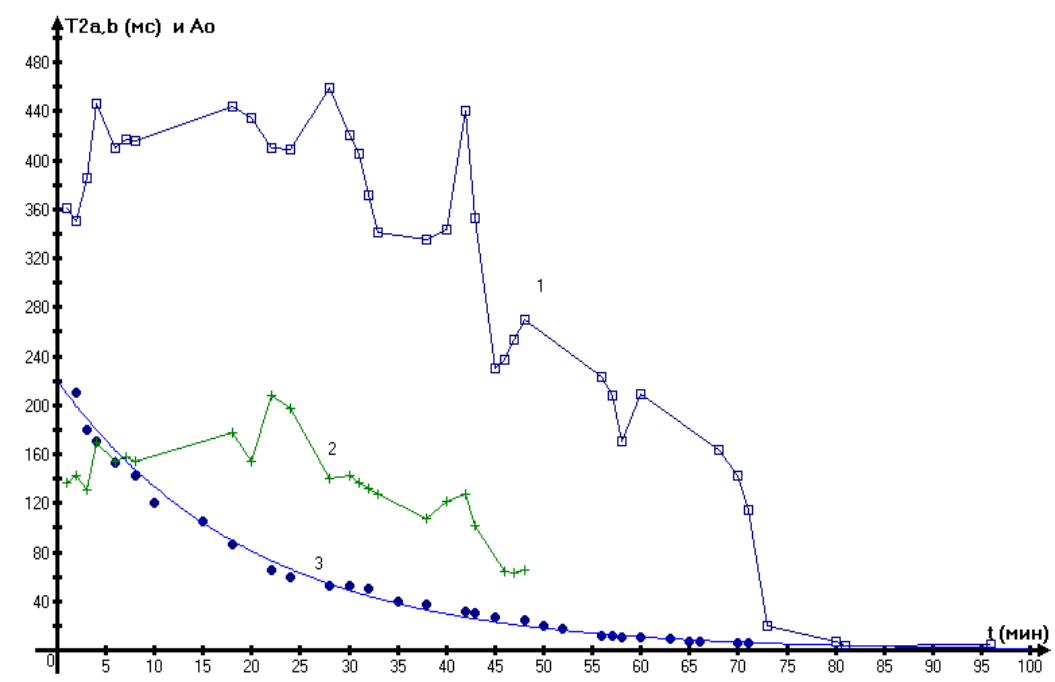

Figure 6. Curves $1,2-T_{1 \mathrm{~A}}$; curves $3,4-T_{2 \mathrm{~A}} ; 5,6-T_{2 \mathrm{~B}}$

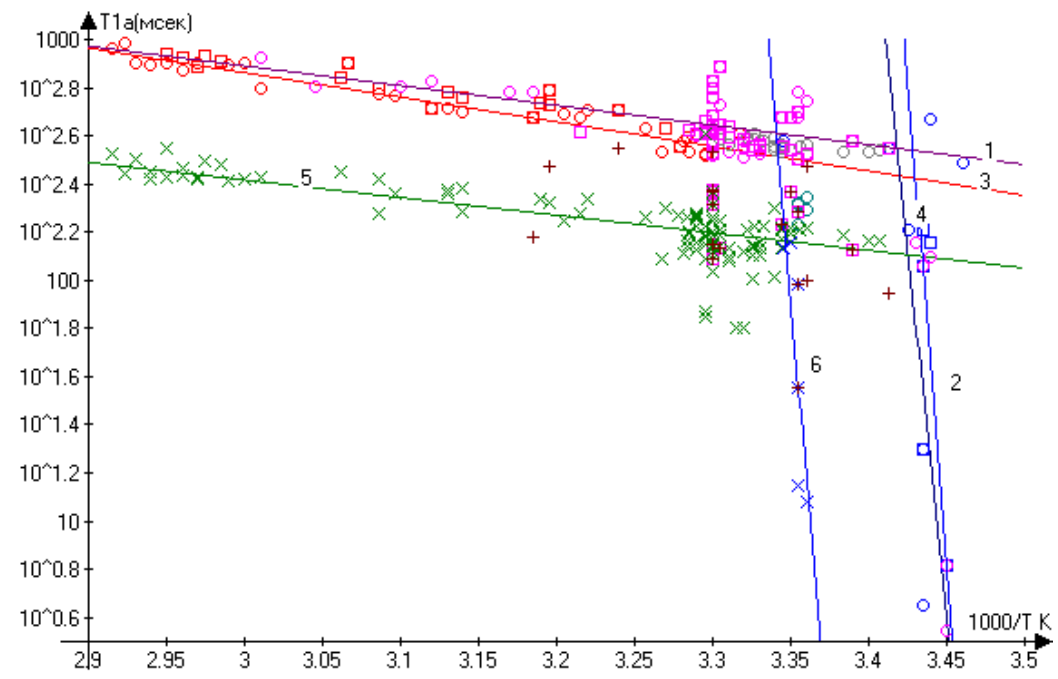

Figure 7. Curves $1-T_{2 \mathrm{~A}}$; curves $2-T_{2 \mathrm{~B}} ; 3-A_{0}$ 
Relaxation rate $\left(T_{1,2}\right)^{-1}$ of water protons has two contributions: intramolecular

$$
\left(T_{1,2}\right)^{-1} \text { intra }=3 \gamma^{4} \mathrm{~h}^{2} \tau / 8 \pi^{2} \mathrm{R}_{\mathrm{ij}}{ }^{6},
$$

which characterize relaxation caused by reorientations of water molecules in crystalline structure, and intermolecular contribution:

$$
\left(T_{1,2}\right)^{-1} \text { inter }=\pi \gamma^{4} \mathrm{~h}^{2} \mathrm{~N} \tau_{\mathrm{D}}\left(1+2 \mathrm{a}_{\mathrm{o}} / 5 \mathrm{D} \tau_{\mathrm{D}}\right) / 4 \mathrm{a}_{\mathrm{o}}{ }^{3},
$$

caused by translation diffusion of water in the melt[13]:

where $\gamma / 2 \pi=4256 /$ sec.gauss - gyromagnetic ratio for protons, $h=6,626 \cdot 10^{-34} \mathrm{~J} / \mathrm{s}$ - Plank constant, $N_{\mathrm{I}}=6,75 \cdot 10^{28}$ $\mathrm{m}^{-3}$ - number of spins in $\mathrm{cm}^{3}, a_{\mathrm{o}}$ - average molecular diameter, $R_{\mathrm{ij}}-$ average distance between protons, $\tau_{\mathrm{R}}$ and $\tau_{\mathrm{D}}-$ correlation times of rotational and translational motions $\left(\tau_{\mathrm{D}}\right.$ $\left.=a_{\mathrm{o}} / 12 D\right), D-$ self diffusion coefficient of water molecules. Inter-proton distances $R_{\mathrm{ij}}$ can be calculated using eq(6).

Studied crystal-hydrate $\mathrm{CaCl}_{2} \cdot 6 \mathrm{H}_{2} \mathrm{O}$ is attributed to the crystal type, in which water molecules sited not in the pores or channels, but directly on the ions. That's why the main relaxation is caused by reorientations of water molecules $\left(T_{1,2}\right)^{-1}$ intra connected by hydrogen H-bonds. More long times $T_{1 \mathrm{~A}}$ and $T_{2 \mathrm{~A}}$ of proton phase A are attributed to protons of not crystallized water (upper and right vertical lines), times $T_{1 \mathrm{~B}}$, $T_{2 \mathrm{~B}}$ - to the B phase with some degree of crystal state through $H$-bonds (lower and left vertical line).Alternative relaxation mechanism is not regarded, because translation of water during phase transition till melt is absent. Analysis of this paradox gives opportunity to make a conclusion (as it was noted in [15]), that diffusion is determined not only by the factor of overcoming of activation energy of potential barrier, but depends also from entropy factor, connected with molecular ordering. Salt crystal structure repeat water tetrahedral structure with her $104^{\circ} 27^{\prime}$ angle between $O-H \ldots O$ bonds. As it is seen from fig.6 phase transition in $\mathrm{CaCl}_{2} \cdot 6 \mathrm{H}_{2} \mathrm{O}$ takes place in the oscillating form in wide temperatures range $T=16-26^{\circ} \mathrm{C}\left(10^{3} / \mathrm{T}=3.46-3.375\right)$ and finish at $10^{3} / \mathrm{T}=3.375$ for phase $B$ and at $10^{3} / \mathrm{T}=3.46$ for phase A.

Temperature dependences of $T_{1 \mathrm{~A}}, T_{2 \mathrm{~A}}$ and $T_{2 \mathrm{~B}}$ from $1000 /$ Tare characterized by exponents and in frame of coordinates $\lg T_{1,2 \mathrm{i}}\left(10^{3} / T\right)$ presented for $T_{1 \mathrm{~A}}$ by two lines with individual energies of activation $E_{\mathrm{A}}$ - in high temperature range $10^{3} / T=2,9-3,42\left(19-72^{\circ} \mathrm{C}\right)$ and in low temperature range $10^{3} / T=3,42-3,45\left(17-19^{\circ} \mathrm{C}\right)$.

At $10^{3} / T=3,42\left(17^{\circ} \mathrm{C}\right)$ observed break of $T_{1 \mathrm{~A}}$ dependence. $T_{1 \mathrm{~A}}$ and $T_{2 \mathrm{~A}}$ for temperature ranges $10^{3} / T=2,9-3,42\left(19-72^{\circ} \mathrm{C}\right) \quad$ with correlation coefficients $R^{2}=0,864$ and $R^{2}=0,977$ are described as:

$$
\begin{aligned}
& T_{1 A}=2,2 \cdot 10^{5} \cdot \exp \left(-1,9 \cdot 10^{3} / T\right) \\
& T_{2 A}=3,8 \cdot 10^{5} \cdot \exp \left(-2,1 \cdot 10^{3} / T\right)
\end{aligned}
$$

Dependence $T_{2 \mathrm{~B}}$ has another range of temperature $10^{3} / T=2,9-3,36\left(19-72^{\circ} \mathrm{C}\right)$ and described by equation:

$$
T_{2 B}=8,3 \cdot 10^{4} \cdot \exp \left(-1,9 \cdot 10^{3} / T\right)
$$

Two relaxation times proton phases $A$ and $B$ with different activation energies are observed even in pure water near phase transition [13, c.114]. For high temperature range $E_{\mathrm{A}}$ of pure water protons and $E_{A}$ determined for crystal-hydrate from $T_{1}$ are very close: 3,7 and $3.79 \mathrm{kcal} /$ mole accordingly.

Temporary dependences of relaxation times on fig.7 in $\mathrm{CaCl}_{2} \cdot 6 \mathrm{H}_{2} \mathrm{O}$ during the phase transition are also complicated. Relaxation times of the both phases $A$ and $B$ change in oscillating form. So, on curve 1 (squares) $-T_{2 \mathrm{~A}}$ and on curve 2 (crosses) - $T_{2 \mathrm{~B}}$ six minimums of relaxation times are observed. That is phase transition of crystallization take place not in a moment, but is prolonged for time. The full crystallization at cooling process does not happen at the definite temperature $T=29$ or $30{ }^{\circ} \mathrm{C}$ (as it is reported in literature), but begins at earlier temperatures and goes passing through formation of temporal ordered structures, which gradually increase their degree of ordering and form minimum of $T_{2 \mathrm{i}}$ as it follows from eq.(6). This process gives oscillations of $T_{2 \mathrm{i}}$ before crystallization. Ordering from melt can be attributed to metastable state and for both $A$ and $B$ proton phases this temperature range is approximately in the range $30-35^{\circ} \mathrm{C}$, corresponding to unstable intermediate state, which can be named structure-dynamical phase transition (SDPT). At the end of this range, before the transition to fully ordered (crystal) state, expenditure of the heat is needed. Physically it need additional energy for transformation of water molecules in the more ordered state. According to classical thermodynamics this situation can be expressed by Nernst law:

$$
\Delta \mathrm{F}-\Delta \mathrm{Q}=\mathrm{T} \Delta \mathrm{S},
$$

where $\Delta F, \Delta Q$ and $\Delta S$ are changes of free energy $F$, heat capacity $Q$ and entropy $S$ at temperature $T$. According the law all substances aspire to the minimum of free energy and the most stable substance has minimal $F$. In the case, when $F$ decreases more rapidly, than $Q$, entropy $S$ will also decrease, i.e. substance will come to more ordered form, and this will lead according to eq(6) to decrease of $T_{2 \mathrm{i}}$. The most stable solid state will be reached only at $16{ }^{\circ} \mathrm{C}$, not $29-30{ }^{\circ} \mathrm{C}$ and is ended when $T_{2 \mathrm{~A}}=4 \mathrm{msec}$ in crystal structure.

Decrease of $T_{2 \mathrm{~A}}$ and $T_{2 \mathrm{~B}}$ at SDPT takes place as a result of interproton distance $R_{\mathrm{ij}}$ decrease at every ordered new superstructure formation. Crystalline superstructures ordering are accompanied by exothermic process - emission of heat. Thermoelectrodynamic tension curve on fig.5 obviously demonstrate this.

NMR signal amplitude $A_{\mathrm{o}}$ on fig.7 (curve 3), demonstrate decrease at cooling. As it was mentioned in[16], at cooling take place lay of many structure and phase transitions, and crystallization centers grow by molecules, delayed in media due to viscosity. The process of crystal structure growth can be described by Colmogorov-Avrami equation: [16]:

$$
\mathrm{C}_{t}=1-\exp \left(-Z t^{n}\right)
$$

where $Z$ - constant of crystallization rate, $n$ - coefficient, 
depending from mechanism of crystals formation and growth (Avrami index). At $n=3-4$ three dimension crystals are formed, at $n=2$ (homogeneous nucleation) fibrilliar crystals formed. At $n=1$ takes place formation of one dimensional dendrites.

In our case decrease of the liquid (not crystalled) phase content, characterized by NMR $A_{\mathrm{o}}$ can be described by exponent, and equation for crystallized water is described with correlation coefficient $\mathrm{R}^{2}=0,991$ by equation:

$$
\mathrm{C}_{c}=220,2[1-\exp (-0,05 t)]
$$

Taking in mind, that Avramiindex is $\mathrm{n}=1$, we can supposed, that in $\mathrm{CaCl}_{2} \cdot 6 \mathrm{H}_{2} \mathrm{O}$ crystallization goes through formation of one dimensional dendrites.

It is really so, because fotograph on fig.8, made on technical microscope with $200 \mathrm{X}$ optical increase confirm it. It is seen, that big crystals are formed from parallel oriented a little melted dendrites.
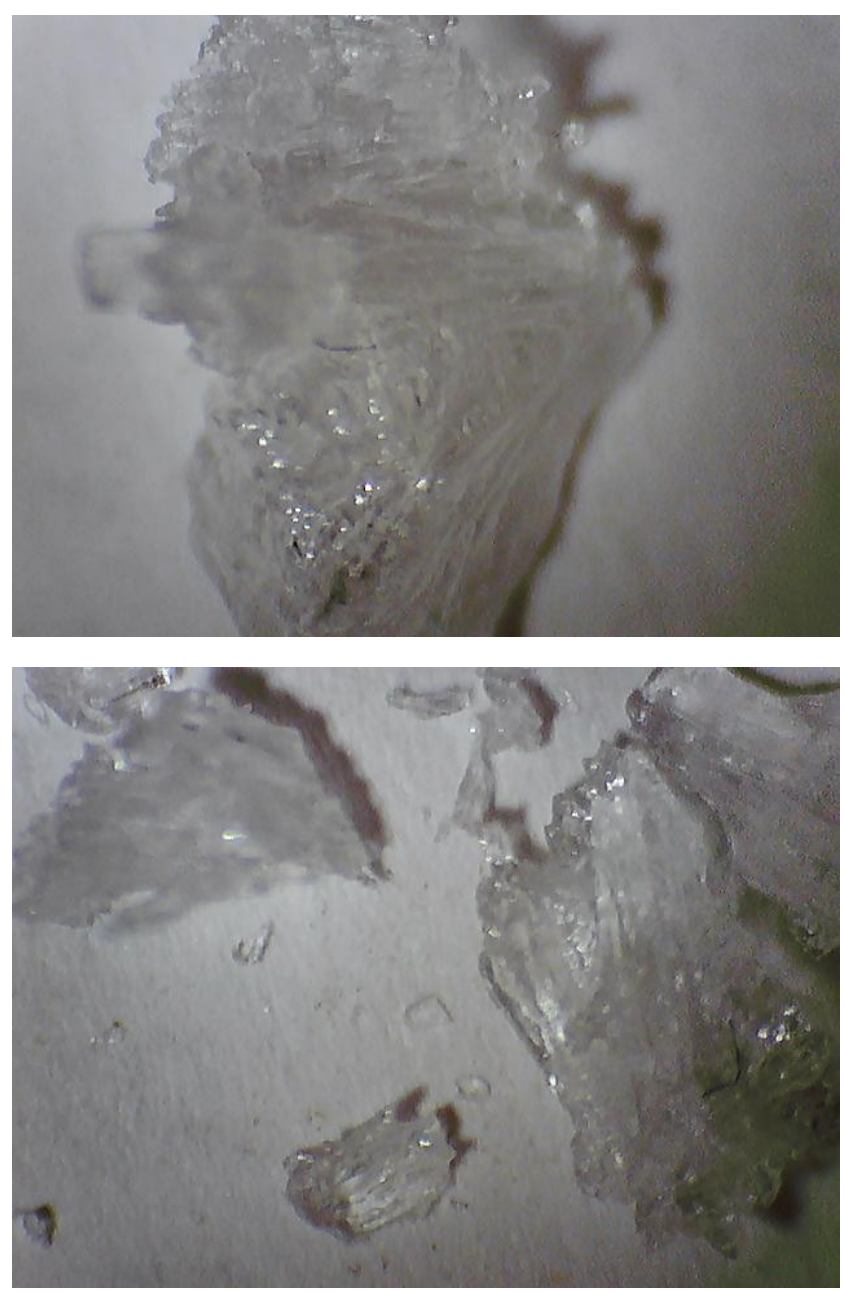

Figure 8. Photographs of crystalls $\mathrm{CaCl}_{2} \cdot 6 \mathrm{H}_{2} \mathrm{O}$

\section{Conclusions}

1. In temperature dependences of $\mathrm{CaCl}_{2} \cdot 6 \mathrm{H}_{2} \mathrm{O}$ relaxation times demonstrate different behavior at the cooling process. Relatively monotone decrease of relaxation times changed by oscillations, followed by the final sharp fall of $T_{2 \mathrm{i}}$ to the value in the crystal state. This is, we suppose, the indication of the ordering of $B$ and $A$ proton phases.

2. Solidification process for hydrated salt on thermoelectrodynamic curve demonstrates sharp increase, corresponding to exothermic heat emission. At the same temperatures the extremes are observed on the thermo-element tension $U_{\mathrm{TE}}(\mathrm{mV})$ dependence. Peculiarities in $T_{2 \mathrm{i}}$ and caloric curves behavior can be explained by structure- dynamical phase transitions (SDPT), which appear as a result of temporary (dynamical) formation and the following destruction (melting) of the supermolecular structures clusters.

3. SDPTs begins at $T=35^{\circ} \mathrm{C}$ and are accompanied by the decreasing of $R_{\mathrm{ij}}$ as a result of ordering and increasing of its density. Final phase transition do not end at $T=$ 29-30 ${ }^{\circ} \mathrm{C}$ (as by literature data), but goes on to the lower temperatures up to $16^{\circ} \mathrm{C}$, passing through formation of temporal structures, which gradually increase their degree of ordering.

\section{REFERENCES}

[1] Ginzburg V.L. http:ginzburg-ocr.narod.ru/online/ginzch2.ht $\mathrm{m}$

[2] Zalba B., Marin J.M., Cabeza F., Mehling H. Review of thermal energy storage with phase change: materials, heat transfer analysis and applications.// Applied Thermal Engineering 23 (2003)251-283

[3] Chemist's reference book, V.1, L.-M.: 1963.

[4] Kashaev R.S.-H., Masiab A.G.N. Patent of Russian Federation on useful model № .2013.

[5] IdiyatullinZ.Sh., Kashaev R.S., Temnikov A.N. Patent of Russian Federation on useful model № 67719, G01N24/05 2006.

[6] IdiyatullinZ.Sh., Kashaev R.S., Temnikov A.N. PatentofRussianFederation on invention№23191138.4.05.20 06.

[7] HahnE.L. // J.Geogr.Res. 65, (1960) 776.

[8] Meiboom S., Gill D. // Review of Scientific Instruments. 29 (1958)688.

[9] Provencher S.W.Comp.Phys.Comm. 27 (1982)229.

[10] PerepuchovA.M. Algorithm of revearse Laplace transformatio $\mathrm{n}$ for complex relaxation data processing. Coll. Of papers Intern. Science conference. St.Petersburg University. 2010.p.98

[11] Brown R.J.S. Information available and unavailable from multiexponentional relaxation dateJ.Magn.Res. 82 (1989) 539-561. 
[12] KashaevR. S.-H., GazizovE.G. operative control of the bitumen and oil components by the NMR-metod. IzvestiyaVUZov. Problemyienergetiki. 2010. №7-8, 7 c.

[13] VashmanA.A., ProninI.S. Nuclear magnetic relaxation and its use in chemical physic. -M:. Nauka, 1979.-235p.

[14] Callaghan J.E., Sullivan S.A. Rev. Sci. Instr. 57, \#10 (1986)
2584-2592.

[15] MosvichYu.I., SergeevN.A., DotcenkoG.I. Study of water mobility in sorrel acid by NMR method. Journal of Structure Chemistry.V.19, №1 (1978) 57-63.

[16] SharplezeA. Crystallization of polymers. MIR publishing. M.: 1968. 